\title{
Thromboelastometry analysis of thrombocytopenic dengue patients: a cross-sectional study
}

Felipe Maia de Toledo Piza ${ }^{1 *}$, Thiago Domingos Corrêa', Alexandre Rodrigues Marra', João Carlos Campos Guerra', Roseny dos Reis Rodrigues ${ }^{1,2}$, Andrea Aparecida Rocco Villarinho1, Valdir Fernandes de Aranda', Sandra Christina Pereira Lima Shiramizo ', Maria Roza de Jesus de Lima', Esper Georges Kallas² and Alexandre Biasi Cavalcanti ${ }^{2}$

\begin{abstract}
Background: Dengue virus infection (DVI) is a prevalent and potentially fatal viral disease associated with coagulopathy. So far, the coagulation profile of DVI patients with thrombocytopenia has not been assessed through a viscoelastic test such as rotational thromboelastometry. We aimed to describe the prevalence and characteristics of coagulation abnormalities in dengue fever outpatients with thrombocytopenia, addressed by both rotational thromboelastometry and conventional coagulation tests.

Methods: This was a cross-sectional study conducted between April $6^{\text {th }}$ and May $5^{\text {th }} 2015$ in São Paulo, Brazil during a dengue outbreak. Thromboelastometry $\left(\mathrm{ROTEM}^{\oplus}\right)$ and the conventional coagulation tests prothrombin time (PT), international normalized ratio (INR), activated partial thromboplastin time (aPTT), thrombin time (TT), platelet count and fibrinogen levels were performed in 53 patients with DVI and thrombocytopenia.

Results: Despite a median interquartile range (IQR) platelet count of $77(63-88) \times 10^{9} / \mathrm{L}$ in DVI patients, conventional coagulation tests and plasma fibrinogen levels were within the normal range. Subjects demonstrated hypocoagulability in 71.7\% (38/53) in INTEM and 54.7\% (29/53) in EXTEM DVI patients. FIBTEM analyses detected only 5.7\% (3/53) with hypocoagulability among this population. The median (IQR) clotting time (CT), clot formation time (CFT) and maximum clot firmness (MCF) on INTEM were, respectively, 177 (160-207) sec, 144 (108-178) sec and 48 (42-52) mm. On EXTEM, median (IQR) CT, CFT and MCF were, respectively, 69 (65-78) sec, 148 (126-198) sec and 49 (44-55) mm. Median (IQR) MCF on FIBTEM was 15 (13-18) $\mathrm{mm}$.
\end{abstract}

Conclusion: Thromboelastometry impairment is highly prevalent in DVI patients with thrombocytopenia, particularly in INTEM and EXTEM analyses, while standard coagulation tests are normal in this setting. Clinical implications remain to be established.

\section{Background}

Dengue is by far the most incident human arbovirus disease [1], with over 2.5 billion people living in high-risk transmission areas [2]. The World Health Organization (WHO) estimates 50-100 million of dengue virus infections (DVI) per year, resulting in 500,000 hospitalizations and 20,000 deaths worldwide $[1,2]$.

\footnotetext{
*Correspondence: felipe.piza@einstein.br

'Department of Intensive Care Medicine, Hospital Israelita Albert Einstein, Av.

Albert Einstein, 627/701, $5^{\circ}$ andar, São Paulo CEP: 05651-901, Brazil

Full list of author information is available at the end of the article
}

Dengue hemorrhagic fever (DHF) represents a severe clinical presentation of DVI and is characterized by the presence of varying degrees of hemostatic disorders [3, 4]. Intense and amplified cytokine release, along with the complement activation, result in endothelial dysfunction, platelet destruction and consumption of coagulation factors, which may lead to a life threatening disseminate intravascular coagulation (DIC) $[5,6]$. Indeed, blood coagulation disorders are commonly observed in patients with DHF and dengue shock syndrome $[6,7]$. 
Many studies have assessed the coagulation system in DVI through conventional coagulation tests such as the prothrombin time $(\mathrm{PT})$, international normalized ratio (INR), thrombin time (TT), and activated partial thromboplastin time (aPTT) [3, 6, 8, 9]. Nevertheless, conventional coagulation tests were validated to monitor vitamin $\mathrm{K}$ antagonists and heparin therapy [10, 11]. Although conventional coagulation tests have not been validated to predict and/or to guide therapy in acute (acquired) hemorrhage, they have been widely used for this purpose [10]. Conventional coagulation tests results may take a few hours to be completed and reported, they track the complexity of hemostatic impairment poorly, and most frequently, they reflect late coagulopathy disorders [10-13].

Rotational thromboelastometry $\left(\mathrm{ROTEM}^{\circ}\right)$ is a point of care test that promptly provides $(5-30 \mathrm{~min}$ ) information about the dynamics of clot formation, stabilization and dissolution, reflecting the in vivo hemostasis at the bedside [12]. ROTEM provides more clinically useful and reliable information than the conventional coagulation tests in critically ill patients $[13,14]$, yielding a graphical presentation of fibrin polymerization process, involving fibrinogen and platelet function, and fibrinolysis [13].

To our knowledge, no study has evaluated the coagulation profile of patients with DVI with rotational thromboelastometry. Therefore, we aimed at describing the prevalence of coagulation abnormalities addressed by both thromboelastometry and conventional coagulation tests in cases of dengue fever outpatients with thrombocytopenia. Additionally, we evaluated the correlation between conventional coagulation tests and thromboelastometry in this population of patients.

\section{Methods}

\section{Study design and setting}

This was a cross-sectional study conducted during a DVI outbreak in São Paulo, Brazil between April $6^{\text {th }}$ and May $5^{\text {th }} 2015$. This study was approved by the University of São Paulo Institutional Review Board [Comissão de Ética para Análise de Projetos e Pesquisas (CAPPesq), approval number: 0652/09]. All patients provided informed consent prior inclusion in this study.

\section{Participants}

Patients were screened at an outpatient clinic established in a neighborhood in the city of São Paulo with high incidence of DVI. Patients with at least $24 \mathrm{~h}$ of fever (axillary temperature $>37.8{ }^{\circ} \mathrm{C}$ ), in addition to a positive dengue virus (DV) specific immunoglobulin IgM/IgG or non-structural protein-1 (NS1) antigen rapid test (DENGUE DUO Bioeasy ${ }^{\oplus}$, Kyonggi-Do, South Korea) and platelet count $<100 \times 10^{9} / \mathrm{L}$ were consecutively included in this study (Fig. 1).

Exclusion criteria included pregnancy, presence of oncologic or hematologic disorders, solid or bone marrow transplantation, secondary thrombocytopenia, previous known coagulopathy, chronic hepatitis $\mathrm{B}$ or $\mathrm{C}$, chronic renal failure and use of anti-platelet therapy or vitamin $\mathrm{K}$ antagonists.

\section{Dengue virus infections triage, support and blood sampling}

All patients who visited the outpatient clinic had their clinical history taken to obtain information on length of time, type and severity of symptoms and vital signs analysis (arterial blood pressure, axillary temperature and heart rate) (Fig. 2). Demographic data, comorbidities, clinical presentation, vital signs and the need for hospital admission were recorded.

Once DVI was suspected, blood samples were collected and tested for detection of DV-specific IgM/IgG and NS1 antigen (Fig. 2). Additionally, hemoglobin, hematocrit, white blood cell and platelets count were performed (XS-1000i ${ }^{\mathrm{T}}$; Sysmex Roche ${ }^{\bullet}$, Kobe, Japan).

Patients with confirmed DVI and arterial hypotension [systolic blood pressure (SBP) <90 mmHg], fever (temperature $>37.8{ }^{\circ} \mathrm{C}$ ), tachycardia [heart rate $(\mathrm{HR})$ $>100 \mathrm{bpm}$ ) and/or hemoconcentration (hematocrit $>50 \%$ for men or $>48 \%$ for women) were admitted for intravenous (I.V.) fluid administration and/or symptomatic support (Fig. 2). In 53 patients with confirmed DVI and

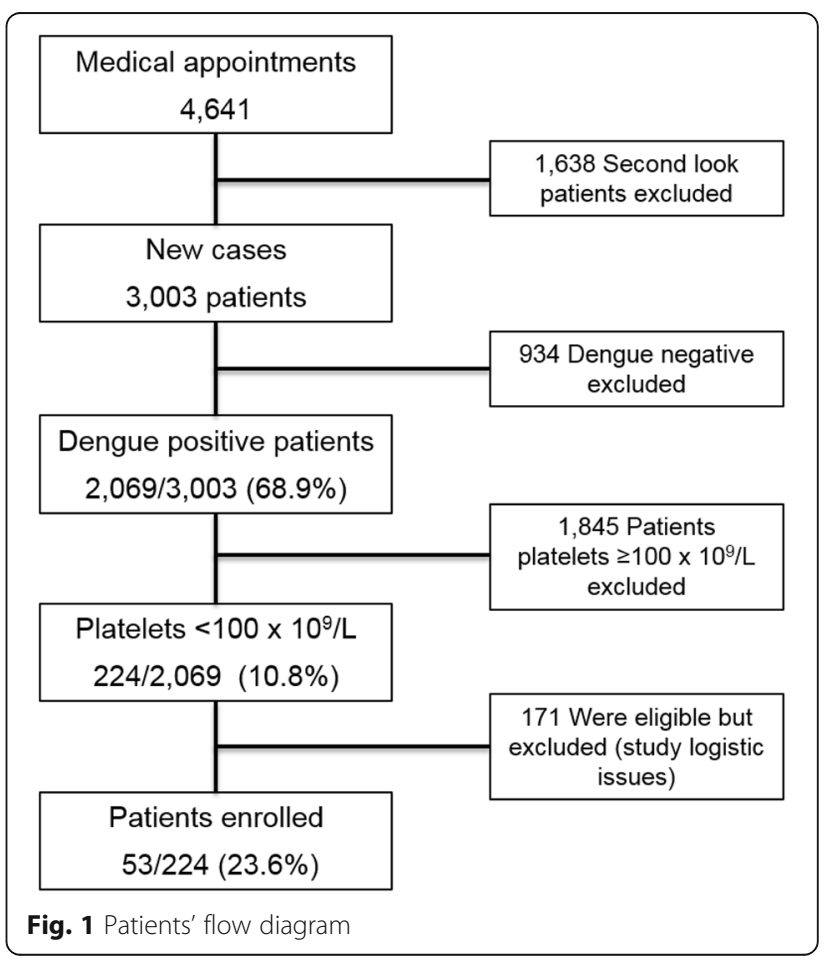




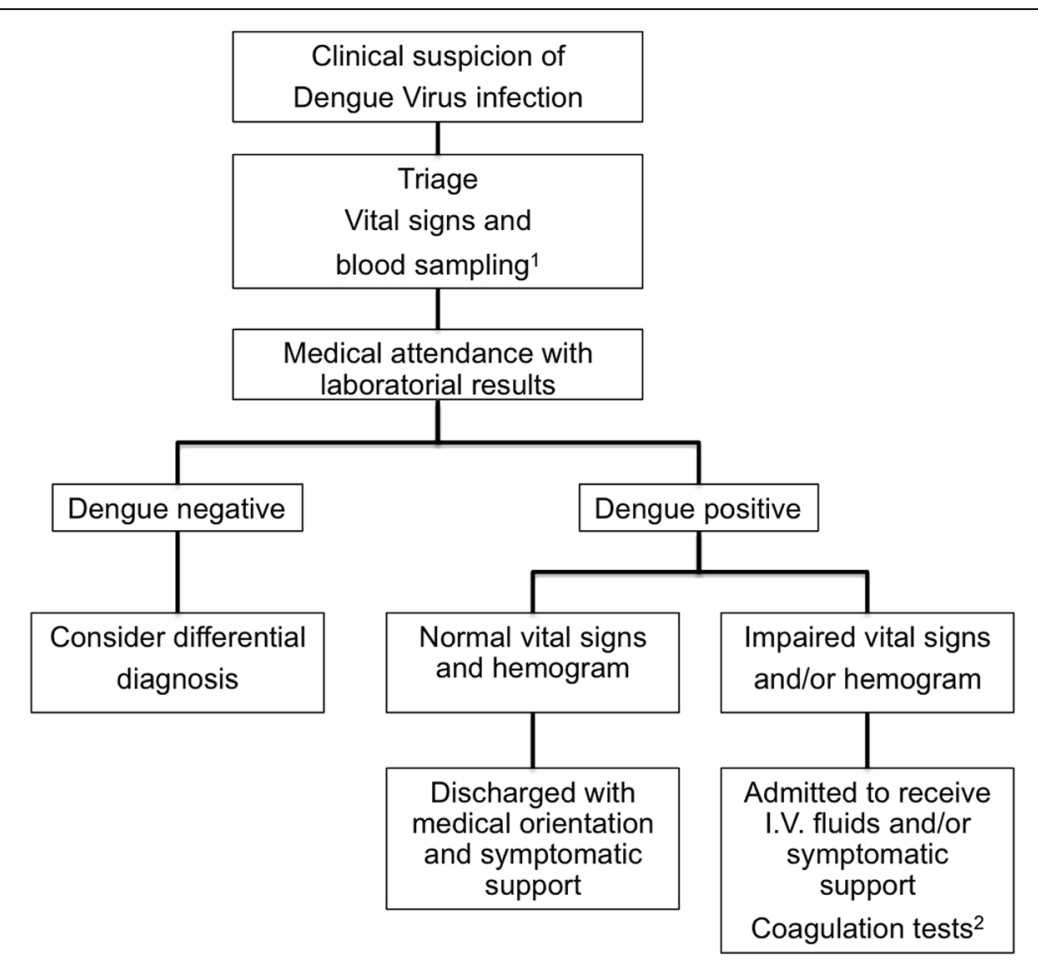

Fig. 2 Patient's flow chart attendance during dengue virus infection outbreak. Legend: ': blood samples for detection of dengue virus specific IgM/lgG and NS1 antigen, hemoglobin, hematocrit, white blood cell and platelet count. ${ }^{2}$ : in the 53 patients with confirmed dengue virus infection and thrombocytopenia (platelet count $<100 \times 10^{9} / \mathrm{L}$ ), conventional coagulation tests (PT, TT, INR and aPTT), serum fibrinogen level, plasma d-dimer levels and rotational thromboelastometry (ROTEM ${ }^{\circledR}$ ) were performed

thrombocytopenia (platelet count $<100 \times 10^{9} / \mathrm{L}$ ), conventional coagulation tests (PT, TT, INR and aPTT) (STA Compact; Stago $^{\oplus}$, Asnières-sur-Seine, France), serum fibrinogen level (Clauss method) (STA Compact; Stago ${ }^{\circledR}$, Asnières-sur-Seine, France), plasma d-dimer level (STA Compact; Stago ${ }^{\circ}$, Asnières-sur-Seine, France) and rotational thromboelastometry (ROTEM ${ }^{\ominus}$; Pentapharm Co., Munich, Germany) were performed.

\section{Thromboelastometry}

Thromboelastometry (ROTEM) assesses the viscoelastic properties of the clot and provides information on the speed of coagulation initiation, kinetics of clot formation, clot strength and breakdown $[14,15]$. Blood samples of $3 \mathrm{ml}$ were collected in citrate tubes $(3.2 \%$; Sarsted $^{\oplus}$, Wedel, Germany) and processed within a period of three hours for thromboelastometry analysis. The analyses were performed by pipetting $300 \mu \mathrm{l}$ of citrated whole blood and $20 \mu \mathrm{l}$ of $0.2 \mathrm{M}$ calcium chloride with specific activators into a plastic cup [16]. Measurement of coagulation in ROTEM was performed after the vertical immersion of a plastic pin into the blood sample. The pin rotates slowly backwards and forwards through an angle of $4.75^{\circ}$. By generation of the first fibrin filaments between the pin and the wall of the test cup, the rotational range of the pin is reduced [13]. The increased restriction of the pin's movement is transferred to a graphical display, a plot that shows changes in the viscoelastic properties of the clot over time [15].

The following parameters were recorded during ROTEM analysis: clotting time [CT; seconds (sec)], which represents the beginning of the test until a clot firmness of $2 \mathrm{~mm}$ is detected, clot formation time (CFT; $\mathrm{sec}$ ), until a clot firmness of $20 \mathrm{~mm}$ has been reached, alpha angle (degrees) represents the slope (tangent) between a CT of $2 \mathrm{~mm}$ and CFT of $20 \mathrm{~mm}$, amplitude 10 (A10; $\mathrm{mm}$ ), which represents the clot amplitude $10 \mathrm{~min}$ after the beginning of clotting and maximum clot firmness (MCF; mm), which represents the greatest amplitude of the thromboelastometric trace and reflects the "strength" of the clot [13-16]. We performed an extrinsically activated thromboelastometric test (EXTEM), a test that uses rabbit brain thromboplastin as an activator; an intrinsically activated thromboelastometric test (INTEM), a test that uses ellagic acid as an activator and a fibrin-based thromboelastometric test (FIBTEM), a test that assesses the fibrin-based clot using both extrinsic activation and addition of cytochalasin $\mathrm{D}$ to inhibit platelets' contribution to clot formation $[13,15]$.

Impaired ROTEM (hypocoagulability) was defined as a clot formation speed above the upper limit of the reference interval (CT INTEM $>246 \mathrm{~s}$ or CT EXTEM $>74 \mathrm{~s}$ ) 
and/or (CFT INTEM $>100 \mathrm{~s}$ or CFT EXTEM $>148 \mathrm{~s}$ ) and/or a MCF below the lower limit of the reference interval (INTEM MCF $<52 \mathrm{~mm}$ or EXTEM MCF $<49 \mathrm{~mm}$ ) and/or alpha angle below the lower limit of the reference interval (INTEM alpha angle $<70^{\circ}$ or EXTEM alpha angle $\left.<63^{\circ}\right)[13,15]$. Finally, impaired ROTEM on FIBTEM was defined as a MCF $<9 \mathrm{~mm}$ [16]. Normal ROTEM was considered if CT, CFT, MCF and alpha angle were within the reference ranges (INTEM CT: 137-246 s, CFT: 40-100 s, alpha angle: 70-83 and MCF: $52-72 \mathrm{~mm}$; EXTEM CT: 42-74 s, CFT: 46-148 s, alpha angle: $63-83^{\circ}$ and MCF: 49$71 \mathrm{~mm}$; FIBTEM MCF: 9-25 mm) [15, 16].

\section{Statistical analysis}

Categorical variables were presented as absolute and relative frequencies. Continuous variables were presented as mean values and standard deviation (SD) or median values with interquartile ranges (IQR) in case of non-normal distribution (tested by the KolmogorovSmirnov test). Continuous variables were compared using independent $t$ test or Mann-Whitney $U$ test in case of non-normal distribution.

Two-tailed tests were used and when $p<0.05$, the test was considered statistically significant. The SPSS ${ }^{\mathrm{mi}}$ (IBM SPSS Statistics for Windows, Version 21.0. Armonk, NY: IBM Corp) and GraphPad Prism version 6.0 (GraphPad Software, La Jolla, California, USA) were used for statistical analyses.

\section{Results}

From April $6^{\text {th }}$ to May $5^{\text {th }} 2015,4641$ medical appointments were scheduled at the outpatient clinic. From those, 3003 were first consultations (Fig. 1). Dengue virus infections were confirmed in 68.9\% (2069/3003) of patients while $10.8 \%(224 / 2069)$ of patients had DVI and thrombocytopenia. Out of those, fifty-three patients [53/ 224 (23.6\%)] were consecutively enrolled in this study (Fig. 1).

The main characteristics of DVI patients included in this study are shown in Table 1. The median age of DVI patients was 32 (IQR, 21-43) years and approximately $60 \%$ were male. The majority of DVI patients $[31 / 42$ (73.8\%)] had no significant previous medical history. Most DVI patients presented with fever and headache and were hemodynamically stable (Table 1 ). Onset of symptoms was acute (median, 4 days; IQR, 2-5), which is consistent with predominance of NS1 positive results [51/53 (96.2\%)]. Bleeding manifestations such as epistaxis, gingivorrhagia, hematemesis, hematuria and melena were reported in only $14.3 \%$ (7/49) of patients (Table 1). A total of $5.8 \%(3 / 52)$ of patients required hospitalization.
Table 1 Main characteristics of participating patients. Values represent \% (n/total) or median (interquartile range [IQR])

\begin{tabular}{|c|c|}
\hline Characteristics & Values $^{a}$ \\
\hline Age, years & $32(21-43)$ \\
\hline Gender, male & $60.4(32 / 53)$ \\
\hline \multicolumn{2}{|l|}{ Comorbidities } \\
\hline None & $73.8(31 / 42)$ \\
\hline Hypertension & $16.7(7 / 42)$ \\
\hline HIV infection & $2.4(1 / 42)$ \\
\hline Prostatic hyperplasia & $4.8(2 / 42)$ \\
\hline Dyspepsia & $2.4(1 / 42)$ \\
\hline \multicolumn{2}{|l|}{ Clinical presentation } \\
\hline Fever & $100.0(53 / 53)$ \\
\hline Headache & $83.0(44 / 53)$ \\
\hline Rash & $36.8(14 / 38)$ \\
\hline Vomiting & $25.5(13 / 51)$ \\
\hline Bleeding manifestations ${ }^{b}$ & $14.3(7 / 49)$ \\
\hline Dehydration $^{c}$ & $11.3(6 / 53)$ \\
\hline Axillary temperature & $37.0(36.1-37.7)$ \\
\hline Systolic blood pressure & $127(115-133)$ \\
\hline Diastolic blood pressure & $80(73-86)$ \\
\hline Heart rate & $93(82-102)$ \\
\hline \multicolumn{2}{|l|}{ Serologic diagnosis } \\
\hline NS1 & $96.2(51 / 53)$ \\
\hline $\lg M$ & $20.8(11 / 53)$ \\
\hline $\lg G$ & $3.8(2 / 53)$ \\
\hline Prior DV infection ${ }^{d}$ & $9.8(5 / 51)$ \\
\hline Yellow Fever vaccination ${ }^{e}$ & $18.9(7 / 37)$ \\
\hline Days after onset of symptoms & $4(2-5)$ \\
\hline Need of hospitalization ${ }^{f}$ & $5.8(3 / 52)$ \\
\hline
\end{tabular}

HIV Human Immunodeficiency Virus, NS1 non-structural protein-1, IgM Immunoglobulin $\mathrm{M}$, IgG Immunoglobulin $\mathrm{G}$; ${ }^{a}$ Totals may not sum to 53 , owing to missing values; ${ }^{b}$ epistaxis, gingivorrhagia, hematemesis, hematuria and melena; ${ }^{c}$ clinical signs in mucosa and skin assessed by medical attendant; ${ }^{d}$ considered if patient acknowledge a prior diagnosis stated by medical service. ${ }^{e}$ : considered if patient acknowledge as a positive previous vaccination status, ${ }^{\text {: }}$ : Unknown in one patient (lost to follow-up)

\section{Laboratorial characteristics}

The main laboratorial characteristics of DVI patients are shown in Table 2. All DVI patients with thrombocytopenia [median (IQR) platelets count: $76(62-88) \times 10^{9} / \mathrm{L}$ ] had normal coagulation tests such as PT, TT, INR and aPTT (Table 2).

\section{Thromboelastometry}

The INTEM and EXTEM analysis were abnormal in, respectively, $71.7 \%(38 / 53)$ and $54.7 \%(29 / 53)$ of DVI patients while FIBTEM was normal in 94.3\% (50/53) of DVI patients (Table 3). DVI patients with impaired 
Table 2 Laboratory and conventional coagulation tests result in dengue virus infection patients. Values are presented as median and interquartile range

\begin{tabular}{ll}
\hline Characteristics & \\
\hline Hemoglobin (g/dL) & $15.1(14.2-16.1)$ \\
Hematocrit (\%) & $42.9(40.6-45.6)$ \\
White Blood Cells $\left(\times 10^{3} / \mathrm{uL}\right)$ & $3.1(2.7-4.5)$ \\
Neutrophil (\%) & $42.3(31.0-48.0)$ \\
Neutrophil (x10 $/ \mathrm{uL})$ & $1.4(1.0-1.8)$ \\
Platelets (x 109/L) & $76(62-88)$ \\
Prothrombin time (sec) & $100(90-100)$ \\
INR & $1.0(1.0-1.1)$ \\
Thrombin Time (sec) & $18.2(17.0-19.5)$ \\
aPTT (sec) & $28.9(26.0-32.5)$ \\
Fibrinogen (g/dl) & $290(267-323)$ \\
D-dimer (ng/ml) & $1330(800-1840)$ \\
\hline
\end{tabular}

INR international normalized ratio, aPTT activated partial thromboplastin time

(hypocoagulability) ROTEM in INTEM and EXTEM assays exhibited higher CFT, lower MCF and alpha angle than DVI patients with a normal ROTEM (Table 3).

Hypocoagulability was found in $28.6 \%$ (2/7) of DVI patients with minor bleeding manifestations in EXTEM and in $57.1 \%(4 / 7)$ patients in INTEM. Out of three patients who required hospitalization, two (66.6\%) exhibited hypocoagulability in INTEM and one $(33.3 \%)$ on EXTEM.

\section{Conventional coagulation tests versus thromboelastometry}

Comparisons between thromboelastometry and conventional coagulation tests are shown in Table 4. Compared
Table 4 Rotational thromboelastometry $\left(\right.$ ROTEM $\left.^{\circledR}\right)$ analysis and conventional coagulation tests. Values represent median (IQR)

\begin{tabular}{clll}
\hline Characteristics & Normal & Impaired & $P$ value \\
\hline INTEM, \% (n/total) & $28.3(15 / 53)$ & $71.7(38 / 53)$ & \\
Platelets (x 109/L) & $90(77-94)$ & $70(57-84)$ & $0.005^{\mathrm{a}}$ \\
INR & $1.1(1.0-1.3)$ & $1.0(1.0-1.1)$ & $0.034^{\mathrm{b}}$ \\
aPTT (sec) & $28.2(26.0-31.8)$ & $29.0(26.0-33.3)$ & $0.867^{\mathrm{b}}$ \\
Fibrinogen (g/dl) & $321(290-355)$ & $278(267-311)$ & $0.021^{\mathrm{b}}$ \\
D-dimer (ng/ml) & $950(320-1510)$ & $1410(950-1900)$ & $0.076^{\mathrm{b}}$ \\
EXTEM, \% (n/total) & $45.3(24 / 53)$ & $54.7(29 / 53)$ & \\
Platelets (x 109/L) & $82(68-91)$ & $69(57-83)$ & $0.052^{\mathrm{a}}$ \\
INR & $1.0(1.0-1.1)$ & $1.0(1.0-1.1)$ & $0.390^{\mathrm{b}}$ \\
aPTT (sec) & $30.3(25.0-32.2)$ & $28.1(26.6-32.8)$ & $0.816^{\mathrm{b}}$ \\
Fibrinogen (g/dl) & $308(278-354)$ & $278(264-300)$ & $0.006^{\mathrm{a}}$ \\
D-dimer (ng/ml) & $950(705-1500)$ & $1600(1220-1990)$ & $0.008^{\mathrm{b}}$ \\
FIBTEM, \% (n/total) & $94.3(50 / 53)$ & $5.7(3 / 53)$ & \\
Platelets (x 109/L) & $77(62-88)$ & $71(64-95)$ & $0.758^{\mathrm{b}}$ \\
INR & $1.0(1.0-1.1)$ & $1.1(1.0-1.1)$ & $0.427^{\mathrm{b}}$ \\
aPTT (sec) & $28.5(26.0-31.8)$ & $33.3(26.7-33.4)$ & $0.254^{\mathrm{b}}$ \\
Fibrinogen (g/dl) & $291(267-323)$ & $278(214-315)$ & $0.520^{\mathrm{b}}$ \\
D-dimer (ng/ml) & $1295(790-1820)$ & $1840(1500-1980)$ & $0.223^{\mathrm{b}}$ \\
\hline
\end{tabular}

INR international normalized ratio and aPTT activated partial thromboplastin time. $p$ values with $\left({ }^{\mathrm{a}}\right)$ independent $t$ test and $\left({ }^{\mathrm{b}}\right)$ Mann-Whitney $U$ test

to DVI patients with normal INTEM, DVI patients presenting with impaired INTEM exhibited lower platelet count, INR and plasma fibrinogen levels (Table 4). Dengue virus infection patients presenting with impaired EXTEM exhibited lower plasma fibrinogen levels and higher d-dimer, while platelets count, INR and aPTT did not differ between the groups (Table 4). Finally,

Table 3 Rotational thromboelastometry $\left(\mathrm{ROTEM}^{\oplus}\right)$ parameters in dengue virus infection patients. Values represent median (IQR)

\begin{tabular}{|c|c|c|c|c|}
\hline Characteristics & All & Normal & Impaired & $P$ value $^{*}$ \\
\hline INTEM, \% (n/total) & $100.0(53 / 53)$ & $28.3(15 / 53)$ & $71.7(38 / 53)$ & \\
\hline Clotting time (sec) & $177(160-207)$ & $166(158-179)$ & $180(161-214)$ & $0.114^{b}$ \\
\hline Clot formation time (sec) & $144(108-178)$ & $98(90-106)$ & $166(131-220)$ & $<0.001^{\mathrm{b}}$ \\
\hline Maximum clot firmness (mm) & $48(42-52)$ & $53(52-55)$ & $45(41-49)$ & $<0.001^{a}$ \\
\hline Alpha angle (degrees) & $69(63-73)$ & $74(72-74)$ & $66(62-69)$ & $<0.001^{a}$ \\
\hline Amplitude 10 (mm) & $41(37-45)$ & $48(47-50)$ & $37(33-42)$ & $<0.001^{\mathrm{a}}$ \\
\hline EXTEM, \% (n/total) & $100.0(53 / 53)$ & $45.3(24 / 53)$ & $54.7(29 / 53)$ & \\
\hline Clotting time (sec) & $69(65-78)$ & $68(61-74)$ & $74(66-84)$ & $0.044^{\mathrm{a}}$ \\
\hline Clot formation time (sec) & $148(126-198)$ & $126(114-140)$ & $197(163-269)$ & $<0.001^{\mathrm{b}}$ \\
\hline Maximum clot firmness (mm) & $49(44-55)$ & $54(52-56)$ & $44(40-48)$ & $<0.001^{\mathrm{a}}$ \\
\hline Alpha angle (degrees) & $68(63-72)$ & $72(68-74)$ & $65(56-69)$ & $<0.001^{\mathrm{b}}$ \\
\hline Amplitude 10 (mm) & $41(35-46)$ & $46(44-48)$ & $36(31-39)$ & $<0.001^{a}$ \\
\hline FIBTEM, \% (n/total) & $100.0(53 / 53)$ & $94.3(50 / 53)$ & $5.7(3 / 53)$ & \\
\hline Maximum clot firmness (mm) & $15(13-18)$ & $16(14-18)$ & $7(7-8)$ & $0.004^{b}$ \\
\hline
\end{tabular}

*: Comparisons between normal and impaired groups. $p$ values with $\left({ }^{(a)}\right.$ independent $t$ test and $\left({ }^{b}\right)$ Mann-Whitney $U$ test 
conventional coagulation tests did not differ between DVI patients with normal or abnormal FIBTEM (Table 4).

\section{Discussion}

This study demonstrated that DVI patients with thrombocytopenia frequently exhibited hypocoagulability assessed by thromboelastometry while conventional coagulation tests (PT, TT, INR and aPTT) and plasma fibrinogen levels remained within reference range.

Our findings contrasted previous retrospective studies, which demonstrated that prolonged coagulation times are frequent and strongly associated with bleeding manifestations in DVI thrombocytopenic patients $[8,9,17,18]$. For instance, Wills and colleagues demonstrated in DHF Vietnamese children that a prolonged aPTT $>30 \mathrm{~s}$ and platelet count $<50 \times 10^{9} / \mathrm{L}$ had an increased risk of bleeding [9]. They also suggested that thrombocytopenia is a mortality predictor in this population of patients [9]. The discrepancy between our findings and those reported by others could be explained, at least in part, by the differences in severity among DVI studied patients [2, 4].

Bleeding complications in DVI patients have been associated with a combination of thrombocytopenia, reduced thrombin formation and increased fibrinolysis $[19,20]$. According to Nimmannitya, even extremely low platelet count, such as $<20 \times 10^{9} / \mathrm{L}$, does not increase bleeding risk except in prolonged shock states [21]. This is a very interesting observation since DVI patients frequently exhibited low platelets in association with impaired platelets function $[4,7,19]$. Platelets are crucial for primary hemostasis as they contribute to thrombus formation [10, 22]. Fibrinogen, the final substrate of coagulation and the ligand of platelet glycoprotein IIb-IIIa complex receptors, enhance platelets function [10, 16]. Therefore, we can assume that the low frequency of bleeding manifestations in thrombocytopenic DVI patients in our study can be explained, at least in part, by maintained plasma fibrinogen levels, as shown in FIBTEM analysis [13, 15].

It is likely that fibrinogen plays a key role in keeping clot strength in DVI patients during the first days of disease $[10,20,22]$. Fibrinogen, the factor I of coagulation system, is the most important numerically and functionally coagulation factor [12, 22]. Fibrinogen represents approximately ninety percent of the total amount of plasmatic coagulation factors and it is the first coagulation factor to fall below a critical value during bleeding and hemodilution [10, 20, 22, 23]. Nevertheless, the critical plasma fibrinogen level associated to increased severity of DVI patients due to major bleeding events, hospitalization and death, needs to be determined $[3,4,9,20]$.
Disseminated intravascular coagulation (DIC) is defined by the presence of four criteria: thrombocytopenia (platelets below $100 \times 10^{9} / \mathrm{L}$ ), high level of products of fibrin degradation (PDF), such as d-dimer, PT prolongation and low plasma fibrinogen level [24]. Our study demonstrated that patients in the first days of DVI already met at least two out of four criteria for DIC (low platelets and high PDF). Studies addressing hemostasis in DHF patients showed that all DHF patients manifested acute type of DIC [19, 20, 25]. Prolongation of aPTT and PT, decreased platelets count, plasma fibrinogen level, prothrombin, factor VIII, plasminogen and antithrombin III activities were observed transiently during acute phase of DHF [9, 20, 25] and they characterize hemorrhagic diathesis of DVI severe patients [3, 4, 20, 21, 25].

Viscoelastic tests allow early and individualized coagulation management in different scenarios, such as in trauma $[26,27]$, liver transplantation $[13,28]$, cardiac $[15,28]$ and neurologic surgeries [16, 29], post-partum hemorrhage $[12,27]$ and in critically ill patients $[22,26,28]$. Nevertheless, dengue treatment is based mainly on supportive care with fluids and electrolytes [2, 4, 30, 31]. Transfusion triggers and therapeutic goals are not consensus in DVI patients $[2,5,30,31]$. A report of four DVI bleeding patients with severe DVI and thrombocytopenia in which desmopressin were administrated, showed clinical improvement and hemorrhage control [32]. Desmopressin is a hormone that stimulates release of Von Willebrand factor (vWF) by endothelial cells [10, 22]. The complex factor VIII (FVIII) and VWF improve platelets aggregation and clot stability [33]. Increased levels of vWF were demonstrated in DVI patients during the first days of disease [19, 33]. FVIII/ vWF complex is likely to play a key hemostatic role during the early course of DVI [10, 22]. Endothelial activation may be responsible for extravascular plasma leakage and shock in severe DVI patients [2-5]. However, in the majority of DVI patients, inflammation and endothelial cell activation may represent a compensatory mechanism for thrombocytopenia, clot impairment and hypocoagulability during the early course of disease due to fibrinogen activation and increased vWF levels, which improve platelet aggregation [33-35].

Another key point in the treatment of DVI patients is the need of high I.V. volume expansion due to intense plasma leakage $[2,30,31]$. Thus, dilution coagulopathy may be present in DVI patients and further aggravate coagulation [2, 22, 34]. A thromboelastometry study showed clot impairment after fluid challenge infusions [36]. A fibrin polymerization deficit is assumed to be one of the major side effects of colloids and crystalloids on coagulation. However, impaired coagulation due to dilution coagulopathy is usually transient and can be partially reversed by fibrinogen concentrate transfusion $[10,36]$. Moreover, colloids 
can also impair thrombus generation [22], decrease factor XIII-fibrin polymer interaction [36] and decrease platelet aggregability and adhesion [10, 11]. This could perpetuate a vicious circle of clot impairment in DVI patients with hypocoagulability secondary to a viral infection [37]. Therefore, we need to keep in mind the importance of individualizing volume expansion in DVI patients presenting with coagulopathy [31-34]. Therefore, a thromboelastometrydriven approach could represent an alternative strategy to manage complex cases of DVI associated with coagulopathy [37-39].

Our study has limitations. First, a small sample of DVI patients was included in this analysis. Nevertheless, to our knowledge, this was the first time DVI patients were analyzed with viscoelastic test such as thromboelastometry. Furthermore, most patients included in this report had primary DVI and were not severely ill, which might have affected and/or ameliorated their conventional coagulation tests results. Second, conventional coagulation tests abnormalities and bleeding disorders could be more pronounced in later stages during the course of disease and therefore not detected by our study. Third, dengue virus infection was confirmed by using immunochromatographic assays, which may lack sensitivity and specificity compared to real time polymerase chain reaction (PCR) or enzyme-linked immunosorbent assays (ELISA) for detection of IgM/IgG antibodies and NS1 antigen [40]. Finally, although Zika and Chikungunya viruses co-infections are well known today, they were unknown when this study was conducted [41]. Since diagnostic tools for Zika virus infection were not available in Brazil when the study was carried out, we cannot rule out Zika virus co-infection in our studied patients.

\section{Conclusion}

Outpatients with dengue virus infection and thrombocytopenia commonly exhibited impaired thromboelastometry despite normal conventional coagulation tests. That suggests viscoelastic tests might have a higher sensitivity to detect early coagulation abnormalities in this population of patients. Long-term outcomes and the question of whether or not transfusion resuscitation algorithms based on viscoelastic tests will improve outcomes in DVI patients with coagulopathy and bleeding needs to be further evaluated.

\section{Abbreviations}

A 10: Amplitude 10; aPTT: Activated partial thromboplastin time; CFT: Clot formation time; CT: Clotting time; DHF: Dengue hemorrhagic fever; DIC: Disseminated intravascular coagulation; DV: Dengue virus; DVI: Dengue virus infection; EXTEM: Extrinsically activated thromboelastometry test; FIBTEM: Fibrin-based thromboelastometry test; HR: Heart rate; INR: International normalized ratio; INTEM: Intrinsically activated thromboelastometry test; IQR: Interquartile range; IV: Intravenous; MCF: Maximum clot firmness; NS1: Non-structural protein-1; PDFs: Products of fibrin degradation; PT: Prothrombin time; ROTEM ${ }^{\oplus}$ : Rotational thromboelastometry test; SBP: Systolic blood pressure; SD: Standard deviation; TT: Thrombin time; vWF: Von Willebrand factor

\section{Acknowledgements}

The authors thank the nurses and laboratory technicians for their supportive care of patients during DVI outbreak. We thank Helena Spalic for proofreading this manuscript.

\section{Funding}

Activator reagents for thromboelastometry analysis (INTEM, EXTEM and FIBTEM) were provided by MedLine ${ }^{\oplus}$, TEM $^{\oplus}$, representation in São Paulo, Brazil.

\section{Availability of data and materials}

The dataset used and analyzed during the current study is available from the corresponding author on reasonable request.

\section{Authors' contributions}

FP designed the study, enrolled patients, recorded clinical data, performed laboratory and statistical analysis and drafted the manuscript; TDC and ARM contributed to the study design, enrolled patients, recorded clinical data, performed statistical analysis and revised the manuscript; AV and VA performed the laboratory analysis; JG, SS and MRL contributed to patients enrollment and reviewed the manuscript, EK contributed to study designed and manuscript production; RRR and ABC designed the study, analyzed the data and contributed to manuscript production. All authors revised and approved the final manuscript version.

\section{Competing interests}

The authors declare that they have no competing interests.

\section{Consent for publication}

Not applicable.

\section{Ethics approval and consent to participate}

This study was approved by the University of São Paulo Institutional Review Board [Comissão de Ética para Análise de Projetos e Pesquisas (CAPPesq), approval number: 0652/09]. All patients provided informed consent prior to inclusion in this study.

\section{Author details}

${ }^{1}$ Department of Intensive Care Medicine, Hospital Israelita Albert Einstein, Av. Albert Einstein, 627/701, $5^{\circ}$ andar, São Paulo CEP: 05651-901, Brazil. ${ }^{2}$ Hospital das Clinicas da Faculdade de Medicina da Universidade de São Paulo, São Paulo, Brazil.

Received: 15 July 2016 Accepted: 14 January 2017

Published online: 19 January 2017

\section{References}

1. Chen R, Vasilakis N. Dengue-quo tu et quo vadis? Viruses. 2011;3(9): 1562-608.

2. Guzmán MG, Kouri G. Dengue: an update. Lancet Infect Dis. 2002;2(1):33-42.

3. Kurane I. Dengue hemorrhagic fever with special emphasis on immunopathogenesis. Comp Immunol Microb. 2007;30(5-6):329-40.

4. Srikiatkhachorn A. Plasma leakage in dengue haemorrhagic fever. Thromb Haemost. 2009:102(6):1042-9.

5. Guzman M. Dengue and dengue hemorrhagic fever in the Americas: lessons and challenges. J Clin Virol. 2003;27(1):1-13.

6. Chuang YC, Lin YS, Liu CC, Liu HS, Liao SH, Shi MD, et al. Factors contributing to the disturbance of coagulation and fibrinolysis in dengue virus infection. J Formos Med Assoc. 2013;112(1):12-7.

7. Hottz ED, Oliveira MF, Nunes PC, Nogueira RM, Valls-de-Souza R, Da Poian AT, et al. Dengue induces platelet activation, mitochondrial dysfunction and cell death through mechanisms that involve DC-SIGN and caspases. J Thromb Haemost. 2013;11(5):951-62.

8. Chua MN, Molanida R, de Guzman M, Laberiza F. Prothrombin time and partial thromboplastin time as a predictor of bleeding in patients with dengue hemorrhagic fever. Se Asian J Trop Med. 1993;24 Suppl 1:141-3. 
9. Wills BA, Oragui EE, Stephens AC, Daramola OA, Dung NM, Loan HT, et al. Coagulation abnormalities in dengue hemorrhagic Fever: serial investigations in 167 Vietnamese children with dengue shock syndrome. Clin Infect Dis. 2002;35:277-85.

10. Brummel-Ziedins KE, Wolberg AS. Global assays of hemostasis. Curr Opin Hematol. 2014;21(5):395-403.

11. Favaloro EJ, Lippi G. Coagulation update: What's new in hemostasis testing? Thromb Res. 2011;127:S13-6.

12. Mallett SV, Armstrong M. Point-of-care monitoring of haemostasis. Anaesthesia. 2015;70 Suppl 1:73-7. e25-6.

13. McMichael MA, Smith SA. Viscoelastic coagulation testing: technology, applications, and limitations. Vet Clin Path. 2011;40(2):140-53.

14. Reikvam H, Steien E, Hauge B, Liseth K, Hagen KG, Storkson R, et al. Thrombelastography. Transfus Apher Sci. 2009;40(2):119-23.

15. Whiting D, DiNardo JA. TEG and ROTEM: technology and clinical applications. Am J Hematol. 2014;89(2):228-32.

16. Stensballe J, Ostrowski SR, Johansson PI. Viscoelastic guidance of resuscitation. Curr Opin Anesthesio. 2014;27(2):212-8.

17. Díaz-Quijano FA. Predictors of spontaneous bleeding in dengue patients: a systematic review of the literature. Invest Clin. 2008;49:111-22.

18. Diaz-Quijano FA, Villar-Centeno LA, Martinez-Vega RA. Predictors of spontaneous bleeding in patients with acute febrile syndrome from a dengue endemic area. J Clin Virol. 2010;49:11-5.

19. de Azeredo EL, Monteiro RQ, de-Oliveira Pinto LM. Thrombocytopenia in dengue: interrelationship between virus and the imbalance between coagulation and fibrinolysis and inflammatory mediators. Mediat Inflamm. 2015, Article ID 313842, 16 pages.

20. Orsi FA, Angerami RN, Mazetto BM, Quaino SK, Santiago-Bassora F, Castro V, et al. Reduced thrombin formation and excessive fibrinolysis are associated with bleeding complications in patients with dengue fever: a case-control study comparing dengue fever patients with and without bleeding manifestations. BMC Infect Dis. 2013, 3(1), article 350.

21. Nimmannitya S. Dengue hemorrahagic fever: disorders of hemostasia. Bangkok, Thailand: Proceeding International Congress of Hemotology, Asia-Pacific Division; 1999

22. Hunt BJ. Bleeding and coagulopathies in critical care. N Engl J Med. 2014; 370(9):847-59.

23. Fries $D$, Martini WZ. Role of fibrinogen in trauma-induced coagulopathy. Brit J Anaesth. 2010;105(2):116-21.

24. Taylor FB, Toh $\mathrm{CH}$, Hoots WK, Wada H. Towards definition, clinical and laboratory criteria, and a scoring system for disseminated intravascular coagulation. Thromb Haemost. 2001;86:1327-30.

25. Funahara $Y$, Sumarmo, Wirawan R. Features of DIC in dengue hemorrhagic fever. Bibl Haematol. 1983;49:201-11.

26. Ganter MT, Hofer CK. Coagulation monitoring: current techniques and clinical use of viscoelastic point-of-care coagulation devices. Anesth Analg. 2008;106(5):1366-75.

27. Schochl H, Nienaber U, Hofer G, Voelckel W, Jambor C, Scharbert G, et al. Goal-directed coagulation management of major trauma patients using thromboelastometry (ROTEM)-guided administration of fibrinogen concentrate and prothrombin complex concentrate. Crit Care. 2010; 14(2):R55.

28. Sniecinski RM, Levy JH. Bleeding and management of coagulopathy. J Thorac Cardiovasc Surg. 2011;142(3):662-7.

29. Perry DJ, Fitzmaurice DA, Kitchen S, Mackie IJ, Mallett S. Point-of-care testing in haemostasis. Brit J Haematol. 2010;150(5):501-14.

30. Rigau-Pérez JG, Clark GG, Gubler DJ, Reiter P, Sanders EJ, Vorndam AV. Dengue and dengue haemorrhagic fever. Lancet. 1998;352(9132):971-7.

31. Singhi S, Kissoon N, Bansal A. Dengue and dengue hemorrhagic fever: management issues in an intensive care unit. J Pediatr. 2007;83(2 Suppl):S22-35.

32. Pea $L$, Roda $L$, Moll F. Desmopressin treatment for a case of dengue hemorrhagic fever/dengue shock syndrome. Clin Infect Dis. 2001;33(9): $1611-2$.

33. Neff AT, Sidonio Jr RF. Management of WWD. Hematology Am Soc Hematol Educ Program. 2014;2014(1):536-41.

34. Martina BE, Koraka P, Osterhaus AD. Denque virus pathogenesis: an integrated view. Clin Microbiol Rev. 2009;22(4):564-81.

35. Ho TS, Wang SM, Lin YS, Liu CC. Clinical and laboratory predictive markers for acute dengue infection. J Biomed Sci. 2013, 20(1), article 75.

36. Kozek-Langenecker SA. Fluids and coagulation. Curr Opin Criti Care. 2015; 21(4):285-91.
37. Saner FH. Rotational thrombelastometry: a step forward to safer patient care? Crit Care. 2014;18(6):706.

38. Karon BS. Why is everyone so excited about thromboelastrography (TEG)? Clin Chim Acta. 2014;436:143-8.

39. Levy JH, Dutton RP, Hemphill 3rd JC, Shander A, Cooper D, Paidas MJ, et al. Multidisciplinary approach to the challenge of hemostasis. Anesth Analg. 2010;110(2):354-64.

40. Vickers IE, Harvey KM, Brown MG, Nelson K, DuCasse MB, Lindo JF. The performance of the SD BIOLINE Dengue DUO ${ }^{\circledR}$ rapid immunochromatographic test kit for the detection of NS1 antigen, IgM and IgG antibodies during a dengue type 1 epidemic in Jamaica. J Biomed Sci. 2015;22:55

41. Zammarchi L, Tappe D, Fortuna C, Remoli ME, Günter S, Venturi G, et al. Zika virus infection in a traveler returning to Europe from Brazil, March 2015 Euro Surveill. 2015;20:(23).

\section{Submit your next manuscript to BioMed Central and we will help you at every step:}

- We accept pre-submission inquiries

- Our selector tool helps you to find the most relevant journal

- We provide round the clock customer support

- Convenient online submission

- Thorough peer review

- Inclusion in PubMed and all major indexing services

- Maximum visibility for your research

Submit your manuscript at www.biomedcentral.com/submit
C Biomed Central 